\title{
USING THE KANO MODEL TO BUILD A MANAGER APP PORTAL ACCOMMODATING THEIR USER PREFERENCES
}

\author{
Jorg H. Mayer, Markus Esswein, Reiner Quick and Sanjar Sayar \\ Darmstadt University of Technology, Hochschulstrasse 1, 64289 Darmstadt, Germany
}

\begin{abstract}
Nowadays, even apps for corporate management are respectable. Manager app portals complement such "run-a-business" apps with apps that make managers' business life easier. The right mix of apps makes the difference. Accommodating the user perspective, the objective of this article is to examine which apps disproportionately influence managers' perception regarding the usefulness of information systems (IS). Applying the Kano model and considering both "analyst-" and "consumer-type" managers, we employ findings from a manager focus group survey to discuss the strongest differentiators: (1) Offer collaboration bars and push notifications for analyst managers. Get consumer managers "online" with news tickers. (2) Make core reports more interactive with drill downs and filters for manager self-service. (3) Take "fun and enjoyment" into account when accommodating managers' business life. (4) Consider that tablets create their own manager use case as a "first-stop information shop."
\end{abstract}

\section{KEYWORDS}

Apps for Managers, Kano Model, IS Design for Use, IS Success, User-Group Preferences

\section{INTRODUCTION}

Mobility is still a visible trend in Information Systems (IS) and companies expect mobile IS to make their workforce more efficient. Smartphones and tablets will be the first "go-to" device for more than 50\% of all users (Gartner, 2018). Hence, multifunctional smart devices should no longer be reduced to a "phone with a calendar." Companies should leverage more. Thanks to Apple's million-dollar slogan "There's an app for that" (Wired, 2010) and SAP's (SAP, 2019) FIORI tiles, even apps for corporate management have been established. However, finance content alone is not sufficient to convince managers to go mobile. One of the managers we interviewed outlined, "I will not use an iPad just to have my financials electronically." Thus, the right mix of both "run-a-business" apps and those that make managers' business life easier are crucial. 
Understanding the perception of IS usefulness is particularly important in the field of management support, where strong idiosyncrasies must be considered. Managers tend to have higher expectations with respect to IS accommodating their user preferences (Volonino et al., 1995). Therefore, IS research must broaden its scope beyond pure deployment to include managers' IS use and impact perspective (Kettinger \& Marchand, 2011).

Powering up their mobile devices, we offer a manager app portal with an intuitive navigation for managerial purposes. We define manager app portals as a combination of apps that conform to a model based on a standard (Heinemann \& Council, 2001). According Shneiderman's (1997) mantra "overview first, zoom and filter, then details-on-demand," app portals have to provide both a personalized "first-stop information shop" and an easy-to-use navigation for detailed information. Such portals promise managers to make fact-driven decisions faster than before-especially when they are mobile (Ostrov, 2014).

Following the task-technology fit theory, Goodhue and Thompson (1995) describe IS success as the degree to which IS accommodate a user's tasks. User preferences describe differences in the way consumer use IS. Based on existing manager user group preferences, we specify "IS fit" as the way different apps (small capsulated software components, Zigurs \& Buckland, 1998) accommodate these preferences. User preferences may imply requirements with respect to how IS should provide functions.

Based on Shneiderman (1997), Al-Kassab et al. (2014) examine the impact of visualization and analytics on managerial decision-making. However, an app portal accommodating managers' user perspective is currently not covered in literature. Thus, the objective of this article is to examine which apps disproportionately influence managers' perception of IS usefulness. We consider managers as either "analysts" (those who primarily work more interactively with IS) or "consumers" (those who primarily consume IS information).

We motivate this article in terms of closing gaps in managers' perception of IS usefulness through a manager app portal. Based on the state of the art (literature review), we apply the Kano model (research model). Findings from a manager focus group reveal the strongest differentiators for successful manager app portals (results). We then discuss our results in manager interviews and present a prototype (synthesis). We end with a summary and avenues for future research.

\section{LITERATURE REVIEW}

In line with vom Brocke et al. (2009) our literature review consists of four steps. Firstly, relevant journals are identified. Secondly, databases are chosen that contain the selected journals. Thirdly, a precise keyword search with a Boolean search string is performed. Fourthly, a backward and forward search is performed in order to find references that refer to or are referred by already identified journals.

By conducting a journal search, we started with a focus on leading IS research outlets according to the London School of Economics (Wilcocks et al., 2008). This approach helps to cover a broader range of relevant articles, i.e. not only papers from mainstream IS journals, but also social studies. We chose the five top journals from each set, namely: MIS Quarterly, Information Systems Research, Information \& Management, Journal of Management Information Systems, and Decision Support Systems, as well as European Journal of Information Systems, Information \& Organization, Information Systems Journal, Journal of 
IADIS International Journal on Computer Science and Information Systems

Organizational and End User Computing, and Journal of Information Technology. We complemented them with journals from Human-Computer Interaction, computer science, systems and software engineering and we added proceedings from ICIS, ECIS, AMCIS, and HICSS. We accessed the journals via EBSCOhost, ScienceDirect, Google Scholar, and AIS Electronic Library. Table 1 shows our Boolean search string.

Our search on titles and abstracts resulted in 461 hits, of which we found 32 to be relevant. We added user satisfaction and adoption as well as IS antecedents, determinants, and elements to our search string as they are associated with IS use (Benbasat \& Nault, 1990). A final back- and forward search led to 90 relevant publications, 23 of which deal with directly applicable requirements. We structured them regarding the elements of IS design theories employed as follows (Walls et al., 1992): (A) User model and effects of use (Benbasat \& Nault, 1990): IS are much less efficient if they neglect the user perspective of managers and remain only deployed IT projects. Therefore, a user-group analysis segments user groups and their characteristics that influence how managers use IS and considers the effects of use occurring to managers. (B) Functional or non-functional user requirements (Sommerville, 2010): User requirements can be defined as prerequisites, conditions, or capabilities needed by managers using IS. Functional user requirements address "what" functions software components are supposed to do, while non-functional aspects reflect "how well" the software components performs within their environment. (C) Guidelines (March \& Smith, 1995): They go beyond requirements and contribute to theories that specify how IS should be designed based on kernel theories.

Table 1. Boolean search string

\begin{tabular}{|l|l|l|l|l|l|l|}
\hline \multicolumn{2}{|c|}{} & \multicolumn{5}{|c|}{ OR } \\
\hline \multirow{2}{*}{\begin{tabular}{l} 
Apps \\
\multirow{2}{*}{$\begin{array}{l}\text { Information } \\
\text { presentation }\end{array}$}
\end{tabular}} & $\begin{array}{l}\text { (Visual) } \\
\text { navigation and } \\
\text { dialog control } \\
\text { Cognitive }\end{array}$ & $\begin{array}{l}\text { User } \\
\text { preferences } \\
\text { fit }\end{array}$ & $\begin{array}{l}\text { User require- } \\
\text { ments, attitudes, } \\
\text { styles, pattern }\end{array}$ & $\begin{array}{l}\text { Use cases, and processing } \\
\text { design } \\
\text { guidelines }\end{array}$ & $\begin{array}{l}\text { User satis- } \\
\text { faction, } \\
\text { adoption }\end{array}$ & $\begin{array}{l}\text { Manager portals, } \\
\text { workplaces, } \\
\text { dash-boards, } \\
\text { cockpits }\end{array}$ \\
$\begin{array}{l}\text { determinants, } \\
\text { elements }\end{array}$ \\
\hline
\end{tabular}

(A) User Model: A rigorous app clustering from managers' perspective is missing: With 34 publications, the state of the art of IS user models is comprehensive. 13 publications deal with cognitive styles and cover techniques for user-group analysis. According to Witkin et al. (1977), we examined two working styles among managers. Analyst managers seek causal relationships, prefer quantitative data, and pay attention to details (Huysmans, 1970). Thus, Management Support Systems (MSS) are preferred for standard reporting but analyst managers want to be able to switch to an interactive, deep-dive mode as well rather than a simple information presentation. Consumer managers pay less attention to details and rely on predefined content.

The remaining 21 publications cover effects of use by differentiating characteristics that impact IS design (age, gender, or expertise) or identifying groups of managers and their IS usage (Powell \& Jonson, 1995). Involving managers in IS design is more relevant than ever (Fteimi, 2017). MSS have a five-decade tradition and represent a class of IS covering Management Information Systems, Decision Support Systems, Executive Information Systems, and Knowledge Management Systems, and Business Intelligence for managers (Carlsson et al., 2009). 
(B) Requirements analysis can be enhanced by considering "fun \& enjoyment:" Papageorgiou and De Bruyn (2010) identified monthly (financial) reporting as a key MSS capability. Associated analyses help managers to investigate details (Bergeron, 1995), e.g., by applying filters or drill downs (Turban et al., 2013) or by creating own reports (Laudon \& Laudon, 2018). A news ticker offers an overview so that managers do not have to collect the information from various sources. Neyem et al. (2012) emphasizes collaboration which offers asynchronous communication such as business emails (Lee-Partridge \& Snyder, 2012) and business calendars (Belkadi et al., 2013; Alvarado et al., 2011). Integrating an office suite is uncommon in MSS, however, it obviously support managers' daily work with text documents, spreadsheets and presentations (Watson \& Frolick, 2006; Lee \& Shim, 2006). Direct messages to colleagues are recognized. Meyer and Dibbern (2012) address textual annotations to numbers on a balance sheet, charts or reports. Herskovic et al. (2011) state that emails "at the push of a button" are important. Riemer et al. (2009) argue that the most sophisticated real-time communication technology is shared office documents. Managers prefer telephone over email to convey confidential information and to express personal sentiments. Video conferencing is the only medium that offers the synchronicity of face-to-face communication and thus should be suitable for personal conversations at a distance (Kim et al., 2018). Hess et al. (2014) include private email into the corporate environment.

Semi-business apps support managers' logistics when travelling (Kaneshige, 2011) and offer a search function. Wixom and Watson (2010) identify web browsers for pervasive MSS. Finally, we identified newspaper or business journal readers (Watson \& Frolick, 2006) and convenience apps such as restaurant finders or weather (Lee \& Shim, 2006). Furthermore, Pijpers et al. (2001) state that manager IS use is related to their perceived fun and enjoyment, manager app portals should incorporate both constitutive apps for corporate management and complementing components, which support managers' collaboration and new mobile business life requirements

(C) Ready-to-use design guidelines are lacking: The publications we reviewed provide both lists of apps without a rigorous basis for their selection and attributes of single apps. Two articles consider managers' IS use situations and apps. We only found one method for clustering MSS user interface apps to examine which ones influence managers' user satisfaction. These findings focus on layouts for desktop PCs (Wu et al., 2011). We define mobile MSS as IS offering services for managers while they move from place to place, especially outside their workplace, where technology is accessible, but not necessarily embedded in the environment.

\section{RESEARCH MODEL}

The Kano model is an adequate approach to identify attractive attributes from a "customer" perspective (Chen et al., 2011) to differentiate between motivators that increase workspace satisfaction and hygiene factors that cause dissatisfaction when absent (Herzberg et al., 1959). The model is widely applied in several industry sectors and business objectives (Luor et al., 2015) mainly because it is appropriate to systematically accommodate managers' user preferences in a detailed manner. Compared to other methods for determining desired product attributes, e.g. preference regression or a conjoint analysis, the Kano model is less fatiguing for respondents. More in detail, a conjoint analysis yields estimates for attribute trade-offs with the help of "partworth" or utility functions for each component such as app clusters in our case and a level of implementation, e.g., basic functionality or full set of features). However, for all 
possible combinations a user evaluation is needed to get focus. As an example, for k-app clusters and $\mathrm{x}$-levels of implementation, a conjoint analysis would require $\mathrm{x}^{\mathrm{k}}$ evaluations, while the Kano model only requires $\mathrm{x} \cdot \mathrm{k}$ evaluations. Hence, it seems better suited for a first screening of promising components. Thus, the Kano model enables researchers to focus systematically on managers' perception of IS usefulness. We follow a two-step approach to reach diverse results. First, we examine the user acceptance and experience. Second, we obtain data from both analyst and consumer managers of several companies.

\subsection{Examine Managers' Perception of IS Usefulness}

We transferred the Kano model to a model of understanding IS designs (Figure 1) and differentiate five categories of apps as follows (Matzler \& Hinterhuber, 1998):

1. Attractive apps ("A") disproportionately influence managers' satisfaction and function as the strongest differentiator in design. Since managers do not expect IS to include these apps, their feature increase managers' enthusiasm. These components show a non-linear relationship between product functionality and user satisfaction and do not have a negative influence.

2. One-dimensional apps ("O") result in satisfaction when present and in dissatisfaction when absent. They impact IS performance regarding a linear (one-dimensional) relation. Considering "the more, the better", managers' user satisfaction increases while the apps improve.

3. Must-be apps ("M") are taken for granted. Their absence strongly dissatisfies managers. However, these basic apps do not have the power to shift managers' user satisfaction beyond a neutral state. The non-linear relationship between product functionality and user satisfaction of these components resembles an opposite to attractive components.

4. Apps that managers do not care about are assigned into the indifferent ("I") category. They show a constant (zero) relationship between product functionality and user satisfaction.

5. For apps in the reverse category ("R") a high degree of achievement results in dissatisfaction. Users who like easy-to-use IS handling might perceive the presence of too many app features as reverse quality. This category is the opposite of the one-dimensional component category.

The first four categories contain components which are expected to be positioned by users. Contrarily, the fifth category can rather be interpreted as a hint that the a priori judgment of which components customers might want was wrong. Figure 1 illustrates how these five categories of apps are classified by means of a Kano questionnaire containing a pair of questions for each app. The left side shows both the first question determining managers' response to an app portal with a proposed app (functional question), and the second question concerning their response to the same portal without this app (dysfunctional question). Here, managers can answer as follows: (1) I dislike the app, meaning I will not use it. (2) I can live with it, meaning I do not like this app, (3) I am neutral. (4) It must be that way, meaning this app is essential and managers should have it. (5) I like it that way very much, meaning it is a great and unexpected differentiator: The right side of Figure 1 demonstrates the classification in one of the five Kano clusters. 
Based on our state of the art, we arrived at 30 apps for the portal design. We structured them in three groups: (1) Besides the constitutive apps for managers' corporate management task, we complement the design with apps (2) for manager collaboration, and (3) for mobile business life.

\subsection{Personal Manager-Researcher Interaction within a Focus Group}

In order to find answers to the Kano questions, our manager focus group consisted of 25 Level 1 and Level 2 managers from eight companies (Table 2). Since 2006, they meet regularly three times a year to discuss trends in corporate management and IS support. The participants consisted of 16 analyst and 9 consumer managers. Taking into account that managers are difficult to attract for surveys, the total number of 25 can be considered as reasonable. Kano interviews were conducted in 30-minute face-to-face interviews. We calculated Cronbach's alpha (Cronbach, 1951) to determine the reliability of our results. Due to the scheme of the questionnaire, the collected data was split and analyzed in two groups (functional and dysfunctional). Smartphones and tablets, as well as analyst and consumer managers were treated separately. With alpha values above 0.7 for both manager types and tablets, the results meet standard requirements for psychometric tests (analyst managers: 0.71, consumer managers: $0.78)$. The scores for smartphones $(0.58,0.55)$ are slightly below this threshold. Based on Cronbach (1951), higher values enhance interpretability, but lower values do not necessarily prevent interpretability. Therefore, we did not discard the results for smartphones.

For validity, content validity is given, due to distribution of our questionnaire to experienced managers that were well informed about the topic. Two pretests were conducted and lead to minor changes. Finally, the structure of the software components in the questionnaire and the components themselves are based on a thorough literature review.

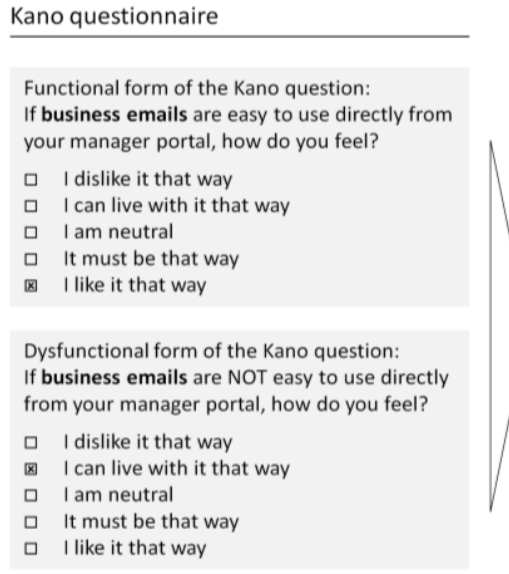

\begin{tabular}{|c|c|c|c|c|c|}
\hline $\begin{array}{l}\text { Dysfunctional form } \\
\text { of the question } \\
\begin{array}{l}\text { Functional } \\
\text { form of the question }\end{array}\end{array}$ & Dislike & Live with & Neutral & Must-be & Like \\
\hline Dislike & Q & $\mathrm{R}$ & $\mathrm{R}$ & $\mathrm{R}$ & $\mathrm{R}$ \\
\hline Live with & $M$ & 1 & I & I & $\mathrm{R}$ \\
\hline Neutral & $M$ & 1 & I & I & $\mathrm{R}$ \\
\hline Must-be & $M$ & 1 & 1 & I & $\mathrm{R}$ \\
\hline Like & o & & A & A & $Q$ \\
\hline
\end{tabular}

Legend: A: Attractive, O: One-dimensional, M: Must-be, I: Indifferent, R: Reverse, Q: Questionable

Figure 1. Kano model for IS design (Matzler \& Hinterhuber, 1998) 
IADIS International Journal on Computer Science and Information Systems

Table 2. Sample characteristics

\begin{tabular}{|l|r|r|l|r|r|}
\hline Position & No. & $\%$ & Sector & No. & $\%$ \\
\hline Executives (L1) & 11 & 44 & Industrial & 17 & 68 \\
\hline Director business dpt. (L2) & 6 & 24 & Financial services & 2 & 8 \\
\hline Director BI department (L2) & 8 & 32 & Other services & 6 & 24 \\
\hline Frequency of IS use & No. & $\%$ & Working style & No. & $\%$ \\
\hline Permanent & 2 & 8 & Analyst & 16 & 64 \\
\hline Multiple times/day & 7 & 28 & Consumer & 9 & 36 \\
\hline Once every day & 10 & 40 & & & \\
\hline 2-3 times/week & 6 & 24 & & Total & 25 \\
\hline Once a week & 0 & 0 & & & \\
\hline
\end{tabular}

\section{RESULTS}

\subsection{Structured Interviews}

We analyzed the results in four ways after determining the number of respondents considering an app "A," attractive, "O," one-dimensional, "M," must be, "I," indifferent or "R," reverse: Firstly, all must-be apps ("M") were integrated in the manager app portal. Secondly, for the remaining apps, we calculated a coefficient to highlight most satisfying apps, the Extent of Satisfaction $(\mathrm{EoS})=\left(n_{A}+n_{O}\right) /\left(n_{A}+n_{O}+n_{M}+n_{I}\right)$. EoS can vary on a scale from 0.00 (no impact on satisfaction) to 1.00 (strong impact). We complement must-be apps by apps in our design with an EoS of 0.30 or more (Figure 2). This is the first number with two decimal places that is significantly larger than zero in a t-test with 24 degrees of freedom and the standard deviation of our sample. We screened our results for apps with a high number of reverse evaluations, because EoS scores are calculated without taking reverse results into consideration. Fourth, we also calculated an Extent of Dissatisfaction (EoD), which considers the most dissatisfying lacks of apps through EoD $=\left(n_{M}+n_{O}\right) /\left(n_{A}+n_{O}+n_{M}+n_{I}\right)$.

Figure 3 presents a two-dimensional combination of EoS and EoD for all apps on the grid of the four Kano categories. The figure provides a classification of the apps as follows: Apps which several users consider a "must-be," a number consider attractive, and the remaining consider apps as indifferent and therefore do not receive the attention they should. They fall through the grid of the first must-be screening and get a relatively weak EoS score of around 0.3 .

(1) Manager collaboration: Starting with the must-be apps on tablets and smartphones, analyst and consumer managers name business emails (app 1.1, numbering according to Figure 2, SC for software component) and business calendar (SC1.2.1). For analyst managers, annotations (SC 1.4.1.) are a must-be, whereas consumer managers consider them as satisfying (0.56; 0.44). One-click collaboration (SC.1.4.3) is the app suited to increasing analyst managers' perception of IS usefulness most. It received an exceptional score on both tablets (0.88) and smartphones (0.56), whereas consumer managers are less interested ( 0.33 on both devices). Notifications on changes (SC1.5.2, 0.81; 0.63) in shared office documents (SC1.5.1, $0.63,0.53)$ are also very attractive for analyst managers on both tablets and smartphones. Consumer managers are rather indifferent $(0.33,0.11)$. Finally, analyst managers ranked an office suite (SC1.3) as attractive (positioned almost in the center of Figure 3, left) on tablets 
(0.44), and less attractive on smartphones $(0.36$, positioned almost all the way to the left of Figure 3, right).

Regarding apps that both manager types consider satisfying, high EoS scores were given to a news ticker (SC1.8) on smartphones $(0.69,0.71)$ and tablets $(0.69 ; 0.63)$. Video calling/ conferencing (SC1.6) is attractive for both manager types on tablets and smartphones $(0.60 / 0.56$; 0.60/0.44). Direct emails (SC1.4.2) received a similar EoS score from analyst (0.63 on tablets and smartphones) and consumer managers (0.67 on both devices). Private emails (SC1.7.1) are relevant for analyst managers $(0.38 ; 0.31)$. Private apps (SC1.7.2) are somewhat satisfying to them $(0.33 ; 0.36)$. Consumer managers are indifferent $(0.11)$. Instant messaging (SC1.5.4) or other users' location (SC1.2.3) do not play a role $(0.25 / 0.07 ; 0.13 / 0.0)$.

Strongest differentiators for manager collaboration: Offer collaboration bars and push notifications for analyst managers. Get consumer managers "online" with news tickers.

(2) Corporate management: Analyst managers evaluated monthly (financial) reporting (SC2.1), management dashboards (SC2.2), and filters (SC2.3.1) as must-be components. Consumer managers, in turn, ranked management dashboards as a must-be on both devices. Filters are considered attractive by consumer managers on both devices $(0.67 ; 0.56)$. Drill-downs (SC2.3.2) are evaluated by both manager types as satisfying on tablets and smartphones (analysts: 0.38 and 0.31 ; consumers: 0.44 on both devices). Creating own reports (SC2.3.3) is only satisfying to some degree for analyst managers on tablets (0.31), but not for consumer managers $(0.13 ; 0.00)$. Finally, a news ticker (SC2.4) is very satisfying for analyst and consumer managers on tablets $(0.63 ; 0.63)$ as well as on smartphones $(0.69 ; 0.63)$.

Strongest differentiators for corporate management: Make core reports more interactive with drill downs and filters for manager self-service.

(3) Mobile business life: Analyst and consumer managers highlight the need for flights and trains apps (SC3.2.1) on tablets and smartphones as must-be apps. A taxi app (SC3.2.2) was evaluated as more satisfying by analyst $(0.38 ; 0.44)$ than consumer managers $(0.33 ; 0.33)$. The former evaluates a web browser (SC3.1.2) as a must-be app and a search engine (SC3.1.1) as satisfying $(0.38 ; 0.38)$ becoming a must-be app (Figure 3$)$. Consumer managers rated this app as satisfying to some degree $(0.33 ; 0.33)$. In turn, business journal (SC3.4.2, 0.94; 0.63) and newspaper readers (SC3.4.1, 0.63; 0.44) are very attractive for analyst managers. The same rating applies to consumer managers on tablets $(0.89 ; 0.78)$. Convenience apps promise further benefits. A weather forecast (SC3.5.1, analyst managers: 0.63 on both devices; consumer managers: 0.56$)$ or a restaurant finder (SC3.5.2, 0.50; 0.44) were evaluated by both manager types as equally attractive on both devices. Besides this predefined selection, managers also mentioned "best steakhouse," a mobile scanner, and point-of-interest maps as helpful for their daily business.

Strongest differentiators for mobile business life: Take "fun and enjoyment" into account when accommodating managers' business life.

(4) Device selection: Eight apps such as video calling/conferencing or business journal readers received higher EoS scores on tablets than on smartphones. The reverse occurred three times for analyst managers and twice for consumer managers (e.g., news ticker for public life). Analyst managers argue that they are more satisfied with tablets than smartphones, because they can use them for sharing office documents simple ad-hoc analyses (create your own reports, SC2.3.3). Consumer managers can start using the app portal on a tablet, especially reading electronic newspapers. Some consumer managers would even use their smartphone instead of a tablet. However, from our interviews we learned that managers do not feel comfortable with smartphones much larger than 5 inches.

Strongest differentiators for device selection: Consider that tablets create their own manager use case as their "first-stop information shop." 
IADIS International Journal on Computer Science and Information Systems

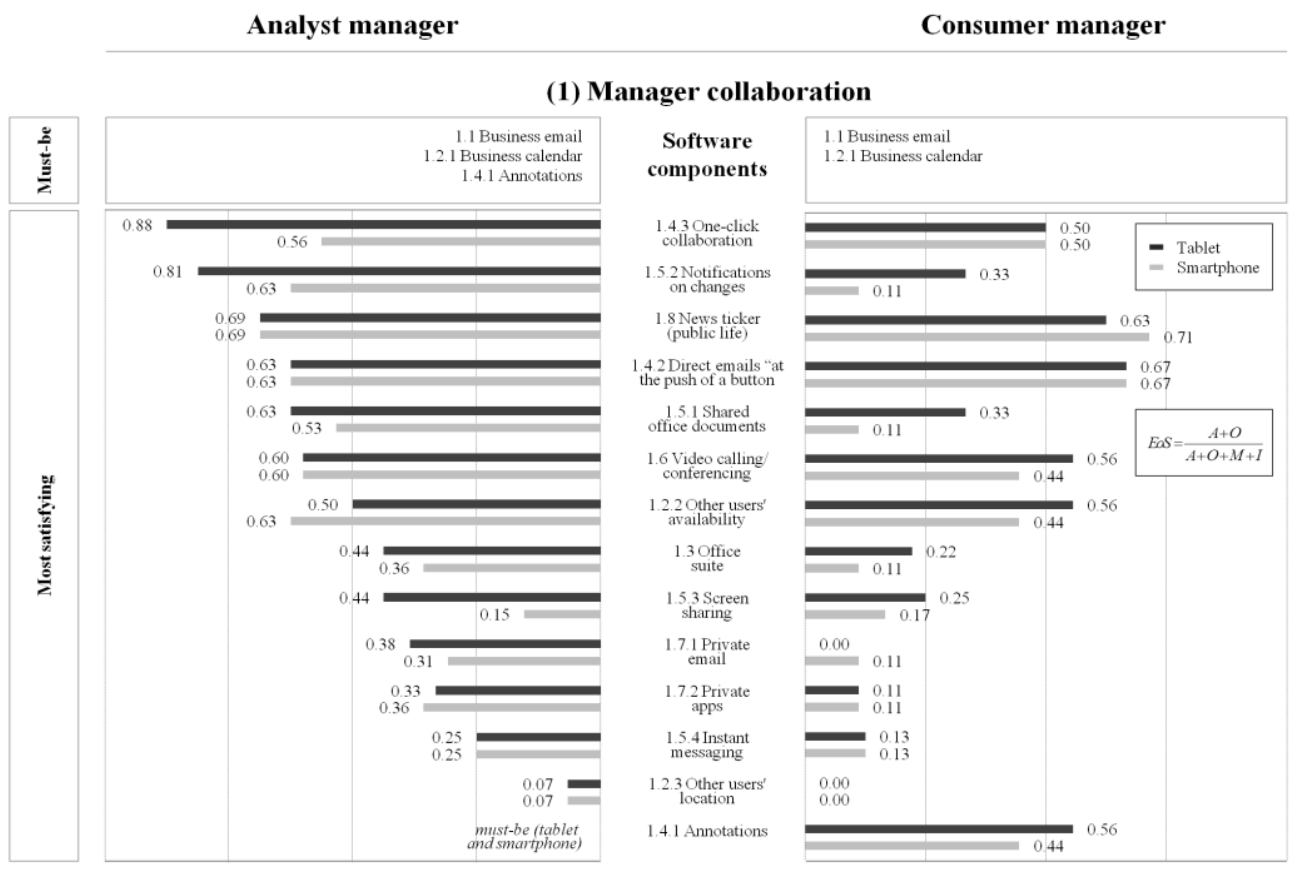

(2) Corporate management
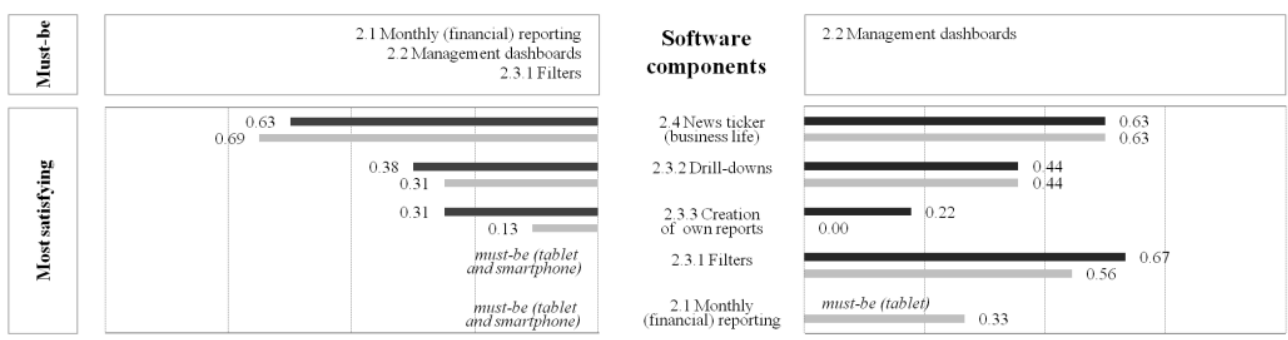

(3) Mobile business life

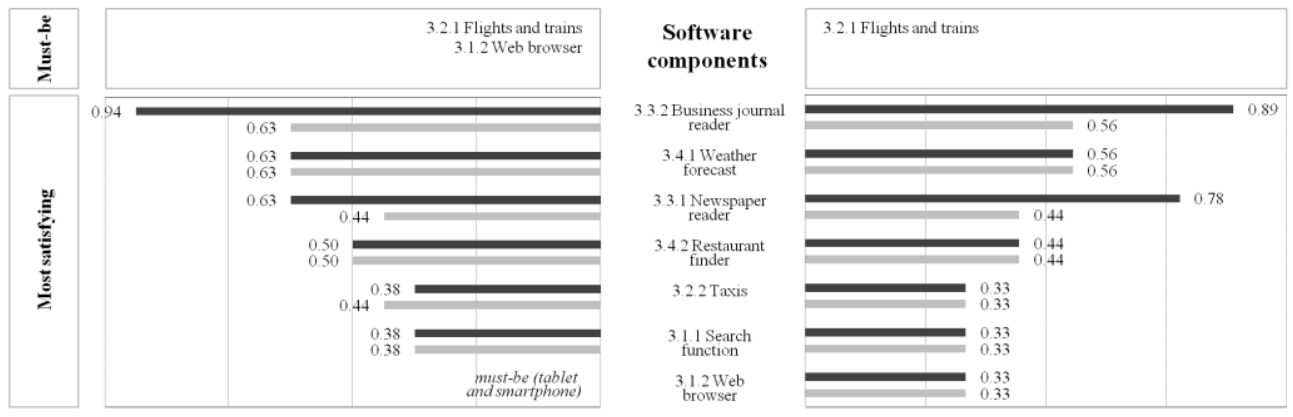

Figure 2. Results of the structured interviews 


\begin{tabular}{|c|c|}
\hline \multicolumn{2}{|c|}{ Tablet } \\
\hline Analyst managers & Consumer managers \\
\hline
\end{tabular}
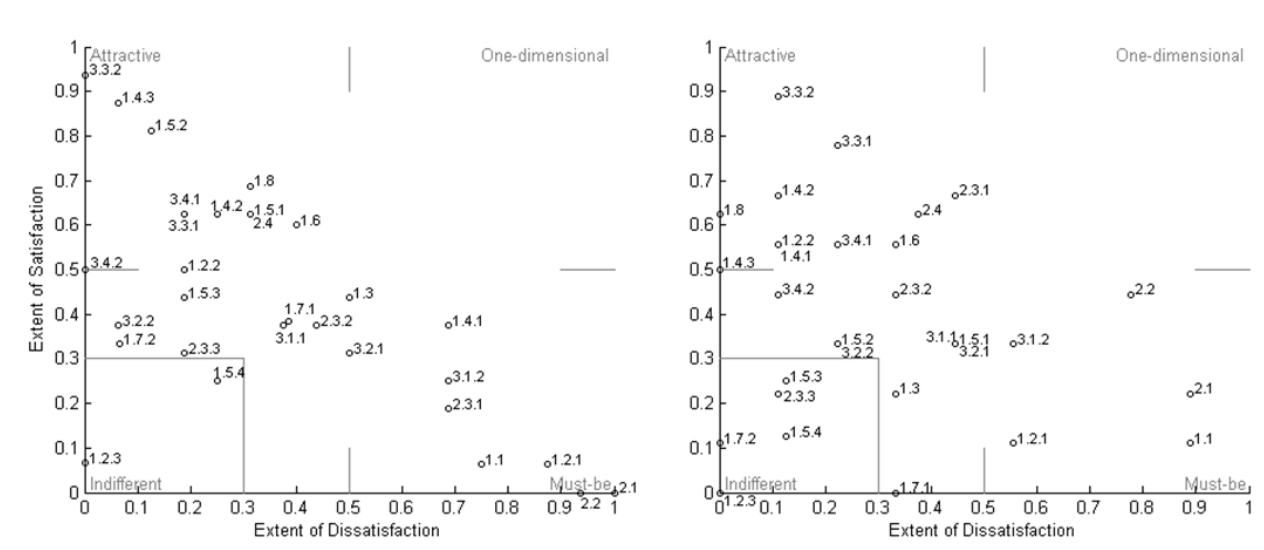

\begin{tabular}{|l|l|}
\hline \multicolumn{2}{|c|}{ Smartphone } \\
\hline Analyst managers & Consumer managers \\
\hline
\end{tabular}
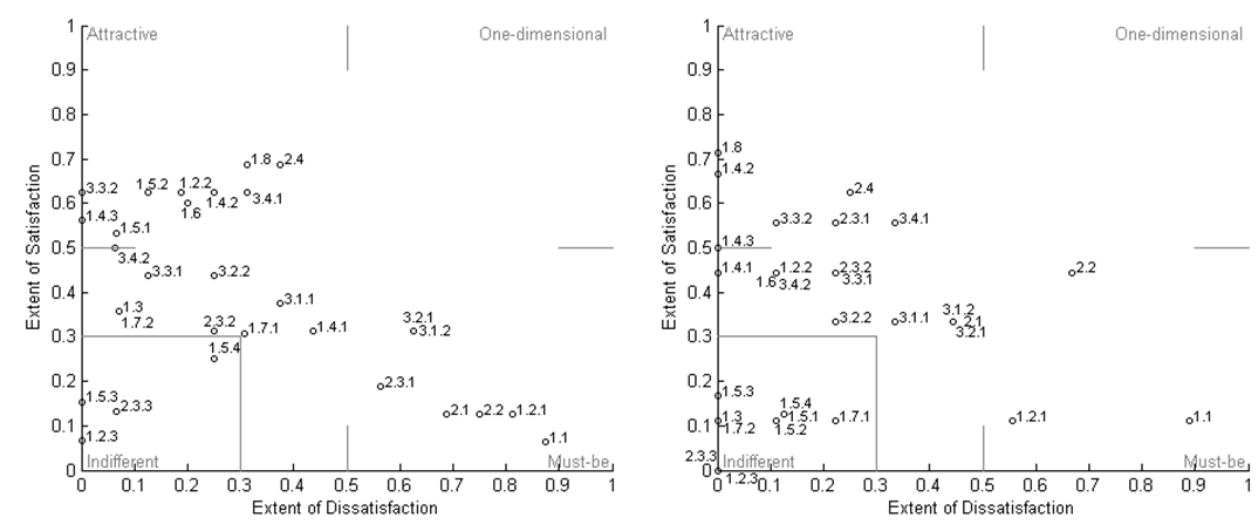

Figure 3. Representation of the results along EoS and EoD for analyst managers

\subsection{Manager (App) Portal Design for Use}

Given these findings, two manager app portal tablet designs were developed, one for analyst managers (Figure 4) and one for consumer managers (Figure 5). Both incorporate the constitutive app cluster "corporate management" and the complementary clusters "manager collaboration" at the left and "mobile business life" at the right side of both figures. In each portal design, the header covers the specific news ticker (public life, SC1.8, business life, SC2.4), the weather app (SC3.4.1) and search engine (SC 3.1.1). Furthermore, business email 
IADIS International Journal on Computer Science and Information Systems

(SC1.1) and business calendar (SC1.2.1) as must-be components. Flight and train apps (SC3.2.1) as well as a taxi app (SC3.2.2) are placed next to each other horizontally, whereas components in the corporate management cluster $(\mathrm{SC} 2.1,2.2)$ are twice as wide to provide more information at a glance.
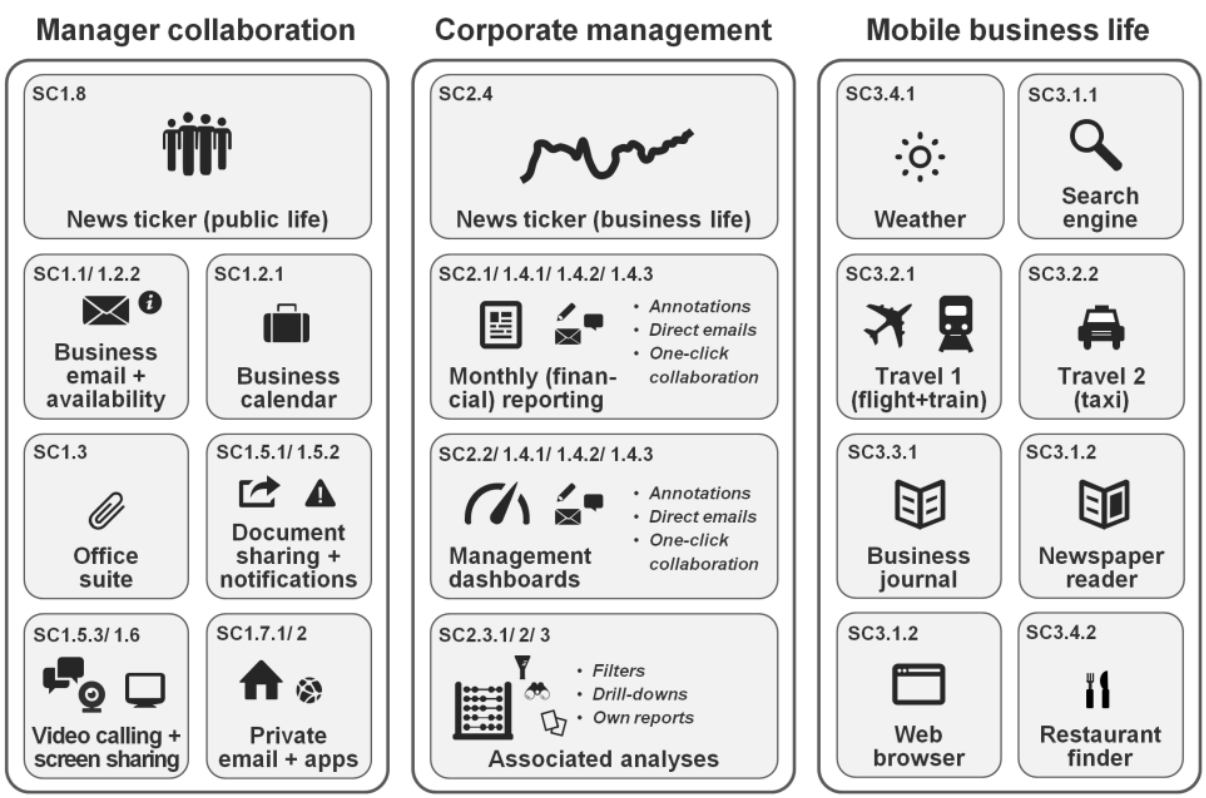

Figure 4. Conceptual design-for-use tablet layout for analyst managers

However, the manager app portal designs for analyst and consumer managers have three differences (Figure 4, 5):(1) Due to the fact that consumer managers evaluated neither screen sharing (SC1.5.3) nor an office suite (SC1.3) as must-be or attractive software components, these blocks have been omitted from their manager collaboration cluster in comparison to the analyst manager app portal. As a result, the shared documents and notifications on shared documents (SC1.5.1 and 1.5.2) block could be attribute more space. (2) While the analyst manager app portal incorporates filters (SC2.3.1), drill-downs (SC2.3.2), and the creation of own reports (SC2.2.3), the consumer manager app portal only provides a limited selection of filters (SC2.3.1) and drill-downs (SC2.3.2). (3) Finally, the analyst manager app portal features private apps, in addition to the private email account (SC1.7) that both portals include.

\section{SYNTHESIS}

We discussed our results in 2018 with two companies improving their manager IS support. Interviews were conducted with the head of management accounting (report provider), a divisional head (recipient) of a chemical company (sales: 50 bn. EUR) and a divisional head of an automotive supplier (30 bn. EUR). 

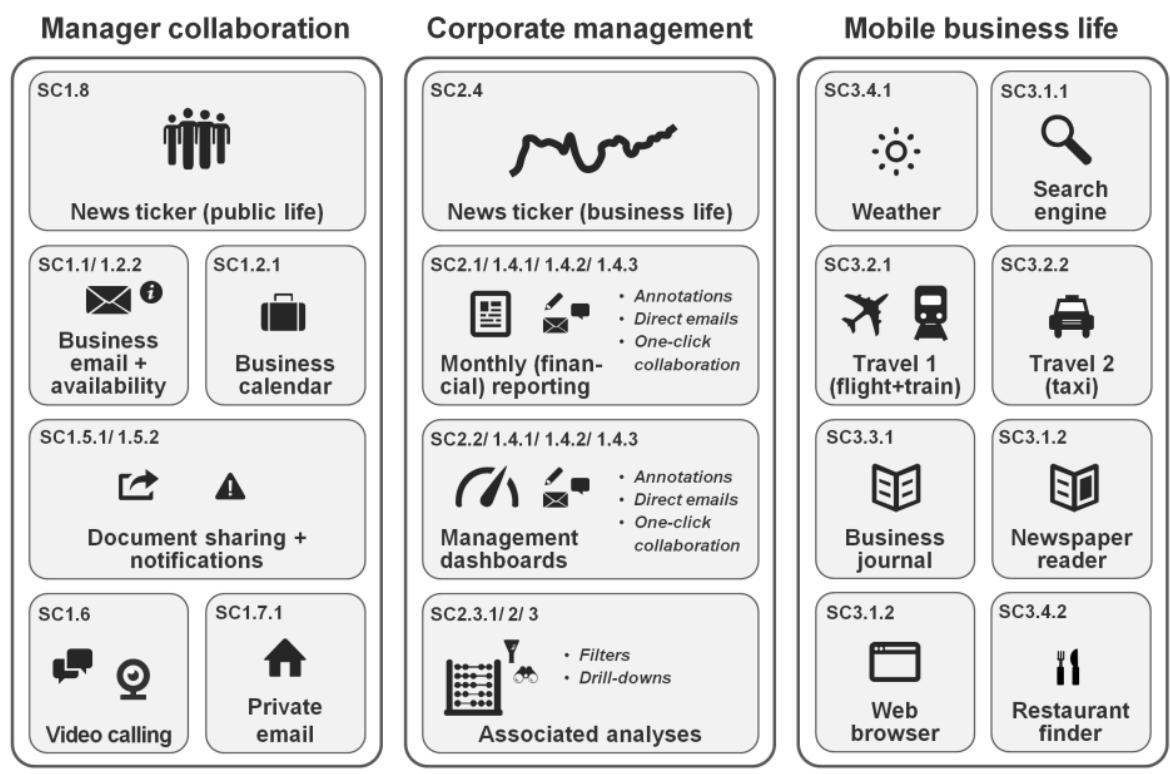

Figure 5. Conceptual design-for-use tablet layout for consumer managers

We proposed the development of a basic manager app portal for consumer managers, which can be adapted to the more individual analyst manager (Krönke et al., 2017). Complementing the Financial Reporting cockpit, an MSS project from 2012 which delivers financial and management accounting reports to Level 1 and Level 2, the CIO of the automotive supplier wanted to align new business requirements with new IS capabilities to proceed with his two purposes. (1) Improve managers' efficiency through more flexible MSS - even when they are mobile. (2) Improve managers' perception of IS usefulness, even for use situations they currently do not expect. Figure 6 shows the implementation of this prototype for an analyst manager on a tablet.

(1) Manager collaboration: Several interviewed managers point out information overload and techno-stress, hampering information accessing, generating, and disseminating information on the road. For instance, the divisional head of the automotive supplier said "I don't want to be bombarded with notifications every minute, draw my attention to critical events and I will be happy." Thus, he confirmed that offering collaboration bars and push notifications on changes to shared office documents is highly relevant, primarily for business purposes with an entertaining factor, e.g., screening car magazines more easily for interesting articles on relevant products and for joy. Likewise, he confirmed the need for a web browser for his single point of access: "Of course, I want to be able to check things on the internet," thus, getting consumer managers "online" with news tickers and one-click emails is relevant as well. In turn, his counterpart from the chemical company was less enthusiastic about restaurant finders and point-of-interest maps: "It is easier to ask the concierge."

Looking forward, remarks about benefits of intelligent automation were made. For example, media monitoring could become interesting to filter global news relevant to the current travel destination(s) or an intelligent push function that screens emails and news of importance and uses different push signals instead of pushing all information to the mobile device. 


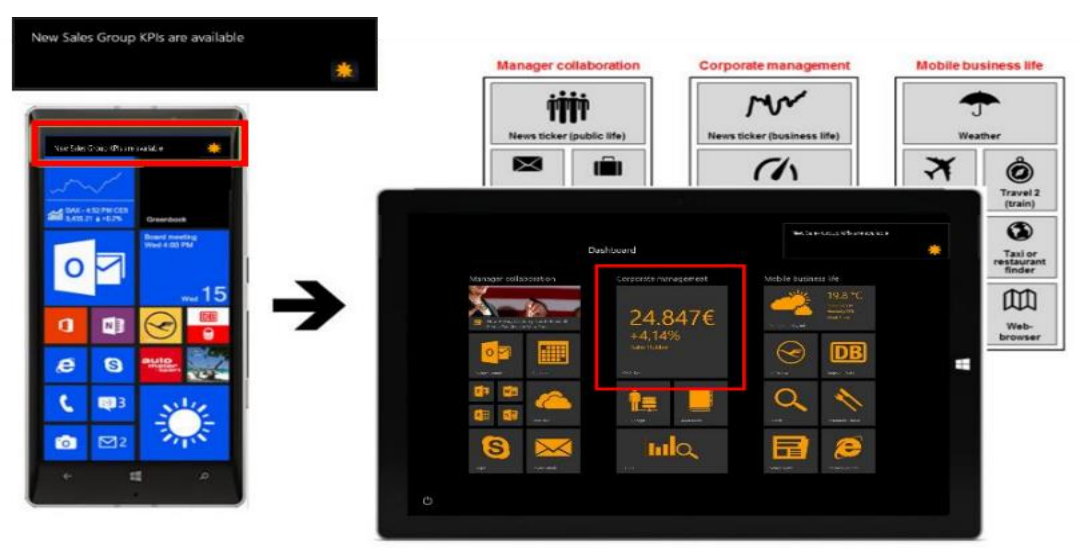

Figure 6. Analyst manager app portal on a tablet with a smartphone push functionality

(2) Corporate management: The head of management accounting was interested, above all, in an integration of his newest predictive analytics ideas in the corporate management cluster. At least core reports should be interactive with drill downs and filters to support manager self-service. All managers stated that our portal design would embrace it. The head of management accounting from the chemical company said, "That is what is on my mind, when I think about manager self-service. The best apps preconfigured to choose from and at a glance."

Supporting more user-driven reports and analyses, eye-tracking was named by the divisional head of the large European automotive supplier. A lot of reports from headquarters are not relevant for the operational business, however, latest market and customer data are sometimes missing. With eye tracking not just the IS navigation could be optimized, but even headquarters could see which parts of reports are really relevant for the operational business and what are the most used navigation features to get to the details. This way, the Controlling function may set up a more user-driven storytelling and commenting.

(3) Mobile business life: Making "fun and enjoyment" more concrete for manager apps portals, the divisional head of the large European chemical company mentioned online business journals and newspaper as well as "around me" apps as a good choice besides the travel and weather apps preconfigured on our approach. Especially online news will help managers to pass waiting times and to no longer depend on calling their assistants - however, just when information is available with a few clicks.

(4) Device selection: Although notebooks are the device of choice at our reference company, their managers' mobile use situations called for a smaller device, so that a powerful tablet was essential for the implementation. This was in line with a comment of one manager: "The smartphone has just the capability to be the "satellite" for my new information management, not bigger than 5 inches and it will not be the single device for my corporate management task." Figure 4 outlined the interplay of smartphones as a first hub of information for alerting and push notifications and powerful tablets. Responding to a push email on a manager's smartphone, he or she can choose the app portal on the tablet or call his or her assistant with a smartphone for further details. As such, in our use case company tablets (a) serve as an advanced PDF reader more efficiently than smartphones do and (b) as an electronic typewriter for complex emailing, especially when office documents are attached, as well as (c) managers' preferred device for simple ad-hoc analysis "on the fly" (Krönke et al. 2017). 


\section{CONCLUSION}

The objective of this article was to examine which apps disproportionately influence managers' perception of IS usefulness. We propose a user-driven manager app portal design and highlighted differences between "analyst-" and "consumer-type" managers. For practice, our findings can serve as a reference for both improving existing designs and future IS designs. For research purposes, the Kano model is an alternative starting point even for other IS designs.

Due to the number of apps the Kano model was best suited to our research. Although we introduced the Kano model to the interviewees, participants' understanding of the dysfunctional questions remains questionable. Future research should ensure that managers understand the Kano model more thoroughly, and, thus, provide more consistent answers. Hauser (1993) stated that 20-30 Kano interviews determine about $90-95 \%$ of all possible requirements. Our investigations were conducted with 25 individuals from eight different companies. Cheng et al. (2016) conducted a study with 22 participants. Our final number of interviews seems reasonable because of two reasons. (1) We interviewed experienced managers providing substantiated answers and (2) motivating this special kind of professionals to participate in surveys is difficult.

Another limitation is our number of IS use factors. Age, gender, education, IS experience, and working styles were not examined, which should be addressed in future work. Incorporating latest research (Madzík, 2018) these might increase the quality of results further. Examining the growing importance of fun and enjoyment when using IS is another avenue for research.

\section{REFERENCES}

Al-Kassab, J. et al., 2014. Information visualization to support management decisions. In International Journal of Information Technology \& Decision Making, Vol. 13, No. 2, pp. 407-428.

Alvarado, B. et al., 2011. Managing user-to-user contact with inferred presence information. Google Patents.

Belkadi, F. et al., 2013. A situation model to support awareness in collaborative design. In International Journal of Human-Computer Studies, Vol. 71, No. 1, pp. 110-129.

Benbasat, I. and Nault, B.R., 1990. An Evaluation of Empirical Research in Managerial Support Systems. In Decision Support Systems, Vol. 6, No. 3, pp. 203-226.

Bergeron, F. et al., 1995. Determinants of EIS use: Testing a behavioral model. In Decision Support Systems, Vol. 14, No. 2, pp. 131-146.

Carlsson, S.A. et al., 2009. An approach for designing MSS: the design science research process and its outcomes. In Proceedings of the 4th International Conference on Design Science Research in Information Systems and Technology. Philadelphia, USA, pp. 1-11.

Chen, L.-S. et al., 2010. C-Kano model: a novel approach for discovering attractive quality elements. In Total Quality Management, Vol. 21, No. 11, pp. 1189-1214

Cheng, J. et al., 2016. Using the Kano Model to Balance Delight and Frustration for an Enterprise Application. In Proceedings of the 2016 CHI Conference Extended Abstracts on Human Factors in Computing Systems. San Jose California, USA, pp. 3021-3027.

Cronbach, L.J., 1951. Coefficient alpha and the internal structure of tests. In Psychometrika, Vol. 16, No. 3, pp. 297-334.

Fteimi N., 2017. A Taxonomy of IS Projects' Knowledge-sharing Mechanism. In Communications of the Association for Information Systems, Vol. 41 No. 26, pp. 611-638. 
IADIS International Journal on Computer Science and Information Systems

Gartner, 2018. Gartner Says by 2018, More Than 50 Percent of Users Will Use a Tablet or Smartphone First for All Online Activities. Available at: https://www.gartner.com/en/newsroom/press-releases/ 2014-12-08-gartner-says-by-2018-more-than-50-percent-of-users-will-use-a-tablet-or-smartphonefirst-for-all-online-activities [Accessed: 16 Jan. 2020].

Goodhue, D. L. and Thompson, R. L., 1995. Task-technology fit and individual performance. In MIS Quarterly, Vol. 19, No. 2, pp. 213-236.

Hauser, J. R., 1993. How Puritan-Bennett used the house of quality. In Sloan Management Review, Vol. 34, Spring, pp. 61-70.

Heineman, G. T. and Councill, W. T., 2001. Component-Based Software Engineering: Putting the Pieces Together. Pearson Education, Addison-Wesley, UK.

Herskovic, V. et al., 2011. The iceberg effect: Behind the user interface of mobile collaborative systems. In Journal of Universal Computer Science, Vol. 17, No. 2, pp. 183-202.

Herzberg, F. et al., 1959. The Motivation to Work. John Wiley, New York.

Hess, T. et al., 2014. Digital Life as a Topic of Business and Information Systems Engineering? In Business \& Information Systems Engineering, Vol. 6, No. 4, pp. 247-253.

Huysmans, J. H., 1970. The Effectiveness of the Cognitive-Style Constraint in Implementing Operations Research Proposals. In Management Science, Vol. 17, No. 1, pp. 92-104.

Kaneshige, T., 2011. 15 Best iPhone Apps for busy CEOs. Available at: https://www.networkworld.com/ article/283 8481/15-best-iphone-apps-for-busy-ceos.html [Accessed 16 Jan. 2020].

Kettinger, W. J. and Marchand, D.A., 2011. Information management practices (IMP) from the senior manager's perspective: An investigation of the IMP construct and its measurement. In Information Systems Journal, Vol. 21, No. 5, pp. 385-406.

Kim H. et al., 2018. Unpacking organizational awareness: scale development and empirical examinations in the context of distributed knowledge sharing. In Journal of Applied Communication Research, Vol. 47, No. 1, pp. 47-68.

Krönke, B. et al., 2017. Manager App Portal at Continental: A Content, Collaboration, and Convenience App Selection That Works. In CONTROLLING - Zeitschrift für erfolgsorientierte Unternehmenssteuerung, Vol. 29, No 5, pp. 36-45.

Laudon, K.C. and Laudon, J.P., 2018. MIS: managing the digital firm. Pearson, Harlow, UK.

Lee, C.-P., Shim, J., 2006. An empirical study on user satisfaction with mobile business applications use and hedonism. In Journal of Information Technology Theory and Application (JITTA), Vol. 8, No. 3, pp. 57-74.

Lee-Partridge, J. E. and Snyder, J., 2012. Using the Layered Model to Understand Employee Selection of Information and Communication Channels for Information and Knowledge Sharing in Project Teams. Proceedings of the Conference on Information Systems Applied Research, USA, pp. 1508.

Luor, T. et al., 2015. Contribution to quality research: a literature review of Kano's model from 1998 to 2012. In Total Quality Management \& Business Excellence, Vol. 26, No. 3-4, pp. 234-247.

Madzík, P., 2018. Increasing accuracy of the Kano model - a case study. In Total Quality Management \& Business Excellence, Vol. 29, No. 3-4, pp. 387-409.

March, S.T., Smith, G. F., 1995. Design and Natural Science Research on Information Technology. In Decision Support Systems, Vol. 15, No. 4, pp. 251-266.

Matzler, K. and Hinterhuber, H.H., 1998. How to make product development projects more successful by integrating Kano's model of customer satisfaction into quality function deployment. In Technovation, Vol. 18, No. 1, pp. 25-38.

Meyer, P. and Dibbern, J., 2012. Awareness Functions - A Study about Social Media in Virtual Teams. In Proceedings of the European Conference on Information Systems, Barcelona.

Neyem, A. et al., 2012. A reusable structural design for mobile collaborative applications. In Journal of Systems and Software, Vol. 85, No. 3, pp. 511-524. 
Ostrov, P., 2014. Sales Analytics: Data Driven Forecasting for Better Quota Attainment. Available at: https://www. Aberdeen.com/cmo-essentials/sales-analytics-data-driven-forecasting-for-better-quotaattainment-2 [Accessed: 16 Jan. 2020].

Papageorgiou, E., De Bruyn, H., 2010. Creating Strategic Value Through Executive Information Systems: An Exploratory Study. In Proceedings of the 3rd European Conference on Information Management and Evaluation, Gothenburg, Gothenburg, Sweden, pp. 380-399.

Pijpers et al., 2001. Senior executives' use of information technology. In Information and Software Technology, 43(15), 959-971.

Powell, P.L. and Johnson, J., 1995. Gender and DSS Design: The Research Implications. In Decision Support Systems, Vol. 14, No. 1, pp. 27-58.

Riemer, K., et al., 2009. eCollaboration: On the nature and emergence of communication and collaboration technologies. In Electronic Markets, Vol. 19, No. 4, pp. 181-188.

SAP, 2019. Reimagine the SAP user experience with SAP FIORI. Available at: https://www.sap.com/ products/fiori.html [Accessed: 8 Aug. 2019]

Shneiderman, B., 1997. A grander goal: A thousand-fold increase in human capabilities. In Educom Review, Vol. 32, No. 6, pp. 4-10.

Sommerville, I., 2010. Software Engineering. Pearson, München

Turban, E. et al., 2013. IT for management: Advancing sustainable, profitable business growth. Hoboken. NJ: Wiley.

Volonino, L. et al., 1995. Using EIS to respond to dynamic business conditions. In Decision Support Systems. Vol. 14, No. 2, pp. 105-116.

Vom Brocke, J. et al, 2009. Reconstructing the Giant: On the Importance of Rigour in Documenting the Literature Search Process. In Proceedings of the 17th European Conference on Information Systems, pp. 2206-2217.

Walls, J.G. et al., 1992. Building an Information System Design Theory for Vigilant EIS. In Information Systems Research, Vol. 3, No. 4, pp. 36-59.

Watson, H.J. and Frolick, M. N. 2006. Determining information requirements for an EIS. In MIS Quarterly, Vol. 17, No. 3, pp. 255-269.

Willcocks, L. et al., 2008. The Ranking of Top IS Journals: A Perspective from the London School of Economics. In European Journal of Information Systems, Vol. 17, No. 2, pp. 163-168.

Wired, 2010. Apple Registers Trademark for "There's an app for that". Available at: https://www. wired. com/2010/10/app-for-that [Accessed: 16 Jan. 2020].

Witkin, H. A. et al., 1977. Field-Dependent and Field-Independent Cognitive Styles and Their Educational Implications. In Review of Educational Research, Vol. 47 No. 1, pp. 1-64.

Wixom, B. H. and Watson, H.J., 2010. The BI-Based Organization. In International Journal of Business Intelligence Research, Vol. 1, No. 1, pp. 13-28.

Wu, C.-S., et al., 2011. User Acceptance of Wireless Technology in Organizations: A Comparison of Alternative Models. In Computer Standards \& Interfaces, Vol. 33, No. 1, pp. 50-58.

Zhang, P. et al., 2002.: AMCIS 2002 Panels and Workshops I: HCI Research in the MIS Discipline. In Communications of the Association for Information Systems, 9, pp. 334-355.

Zigurs, I. and Buckland, B. K., 1998. A theory of task/technology fit and group support systems effectiveness. In MIS Quarterly, Vol. 22, No. 2, pp. 313-334. 